\title{
Traductology, linguistics, and culture: the contrastive function of omissions in English-Chinese translations of the intercultural collision in Little Red Riding Hood
}

\author{
Qiuyang $\operatorname{Pan}^{*}$
}

\begin{abstract}
The study examines omissions in the English version of Little Red Riding Hood in contrast to the Chinese one. The research is aimed at studying the linguistic effects of inculturation and the choice of translation strategies to convey a truthful intercultural component. The study examines the Little Red Riding Hood story by Leray (2011) translated into Englishand Chinese languages. The Chinese version of the story was edited and published by Green and Green (1953). The analysis of the translation in a cultural context is based on the omission strategy. The analysis of semantically redundant words and sentences in the English version of Little Red Riding Hood has been carried out in contrast to the Chinese one, where no omissions were found. The purpose of the study is to analyze the relationship between the versions of Little Red Riding Hood and the evolution of European and Chinese moral ideology. The novelty of the research lies in the fact that two translations are considered in the context of the Tehrani's (2013) method using a phylogenetic approach and the strategy of omission to determine moral codes. As a result of a comparative analysis of the target translation, ten omissions were found: four brief descriptions and six complete omissions. The omission strategy reflected the cross-cultural and informative ideological features of the two cultures. Adhering to the phylogenetic concept by Tehrani, the target language of Little Red Riding Hood was identified as English because the Chinese version of the story was translated from English (Zhengzhong Bookstore, 1967). There are also some distinguishing characteristics of the initial collision: the characteristics of the protagonist, the characteristics of the villain, the methods of deceiving the future victim by the villain and the ending options. The folk European collision of the fairy tale originates from the story The Wolf and the Children. It is also found in Chinese culture-The Girl and the Tiger; however, it is described at the level of other concepts, which confirms the genetic relationship of intercultural conflict. The nature of the extended Chinese translation testifies to the flexible structure and aesthetics of the style, in which traditions and family values play an important role, while in the English version some elements of culture are omitted due to a different mentality and structure of the language. Chinese culture is characterized by respect for elders, a tribute to traditions, and respect for people who are higher in social status. Undoubtedly, greetings in the English language carry a similar semantic load, but due to the peculiarity of its grammatical structure, omitting or transferring a greeting during translation does not harm the context of communication. Thus, it has been revealed that folk tales are a joint
\end{abstract}

*Correspondence: pan2501520@163.com

English Department, College of Arts and Sciences, Northeast Agricultural University, Harbin, China 
imprint of different cultures. The linguistic progression makes them change and adopt new information in accordance with the mentality of the people. There are three clusters of autonomous versions of the fairy tale: far Eastern, African and European; all of them are based on one common ancestor that has not been yet identified.

Keywords: Ideology, Intercultural translation, Linguistic progression, Omission, Phylogenetic method, Translation strategies

\section{Introduction}

Translation is the basis of inculturation and intercultural exchange [1]. The connection between traductology and language has always been controversial. Experts [1-3] often have a dubious opinion that it is sufficient to know two languages to translate texts. But language by its nature is a system of signs [2]. Translation should convey not only linguistic signs but also cultural information [4]. The combination of these two factors varies from country to country [1]. The concept of cultural information is similar to text stored in a specific format, which should always be studied in the source language to avoid distortion of the information. Effective understanding requires decoding of the source language culture. Having received the source information, the translator relies on the target language and its culture to translate the text; otherwise it may become unreadable [5].

Culture is a multilevel structure, an organic whole with the language [6]. The European school [2] introduces the concept of dominant laws of the first level (society, customs, culture, etc.) and recessive laws of the second level (mentality, psychological habits, value systems, elements of morality, etc.). In contrast to the first group, recessive factors are often an obstacle for the translator [2].

The feature of culture is the skill of learning. The ability to speak a certain language comes naturally. But training is required to acquire cultural skills. In the native language environment, these two processes are synchronized [7]. It is not comprehensive to perceive culture in a mono-cultural context. The Romanian school of traductology considers culture as linguistic progression [1]. Translation plays a mediating role in introducing foreign terms into the target language [1]. Chinese today is characterized by a huge number of Japanese borrowings [8]. And the terms of Western origin have been recently often translated phonetically, for example 秀 (xiù-show), 酷 (kù-cool), 蒙太奇 (méngtàiqí-editing), 香香槟 (xiāng xiāngbīn-champagne) [9].

The present study considers multinational collision revealing the metaphorical theme of a predator that in different cultures is endowed with a similar denotationto warn the overly gullible. Thus, the purpose of the study is to analyze the relationship between the versions of Little Red Riding Hood and the evolution of European and Chinese moral ideology. The story Little Red Riding
Hood has a rather complex origin. The challenge of the research is concerned with establishing points of comparison with the original version and the limitation of the study also comes from this fact-according to the current theories [10], the main idea relates to the introduction of the Red Riding Hood collision into Europe from China through the Silk Road. But it should be noted that this opinion is not shared by British scientists [10]. The phylogenetic analysis [10] indicates that China is definitely not the country of origin of the tale. The novelty of the study lies in the fact that two translations are considered in the context of Tehrani's method. Phylogenetic analysis builds on the theory of the possible relationship between traditions and folklore, assuming that the origins of peoples have a long lineage and were central in research carried out by the first folklorists in the nineteenth century [1]. In his phylogenetic approach, the researcher distinguishes fifty-eight versions of the story, all of which have been translated into English. In addition, according to his calculations, there are seventy-two points of comparison, such as the role of the villain, the means he uses, the number of dialogues, the method of salvation, etc. Thus, the analysis is based on the phylogenetic approach of the translation omission strategy to define moral codes.

\section{Background and context}

Research on intercultural communication in the context of translation is aimed at overcoming the limitations of the recipient culture [11]. The expansion of the cultural space of a certain country promotes its dialogue with the rest of the world in a global context [12]. In this respect, the lack of mutual knowledge and geographic isolation between China and Europe gave rise to debates. The modern world has realized the need for in-depth discussions devoted to this issue. Research in the field of intercultural communication is mainly aimed at resolving cultural conflicts between the West and the East [13]. The principle of intercultural exchange is based on fundamental disciplines such as linguistics, anthropology, sociology, computer science and communications, psychology, etc. [14]. Research in this area focuses on the period in the history of mankind when the way of thinking was very isolated between cultures [15]. This was influenced by global geographic, spiritual, and psychological factors: an increase in global urbanization, the 
development of literacy, the development of social moral and ethical foundations, the emergence of incorporation form. Different cultures are very often closed to all types of extraneous elements in order to protect the independence of their own content and values and support the fullness of faith. The perception of alien elements of ancient cultures and their integration into the context of the development of civilizations is important in the intercultural dialogue [16]. Intercultural communication in the context of translation is a method of studying cultural evolution, mutual influences and intercultural exchanges. The intercultural context of China is actually more open than it seems. Today it no longer pursues closeness and isolation [7], and the exchange between the cultures of China and Europe is more than thousands of years of discourse. The creation of a Chinese cultural image and social status required dynamic roles and distributions, cultural exchanges, and linguistic progression. The community of professional translators has become an important field of social advancement in revealing the culture of China. When addressing the problems in translating European literature into China, one has to start with Bible translations, the first translations that penetrated into Chinese culture [17]. When discussing the perfection of translation, the determination of optimal criteria [3] is often noted; however, it should be borne in mind that translation is a variable process. For example, in terms of the content of the texts, only religious texts used to be translated. The next progressive step in the field of translation relates to the cultural field. Translation activity is determined by the time. The plots of the text and translation requirements are gradually changing. Translation is a dynamic interpretation inseparable from the level of the readers' knowledge and desires. Translation without reference to the time can sometimes mislead the reader. For example, the translation of Chinese noble and heroic political sayings resembling lyric poetry, which were very popular until the mid-1990s [18]. These translations misled readers into believing that modern Chinese culture is still in its prime and that the Chinese live in the same conditions as when the War of Liberation or the Cultural Revolution began. In the eyes of local readers, these lyric poems and expressions were rather oldfashioned, while in foreign readers, a spatial distortion of information arose [18]. Globalization at the beginning of the twentieth century unfolded European literature to isolated China. In 1967, a complete structured reference book saw the light [19], which contained the oldest version of the Red Riding Hood in China, first published in 1953. This edition is peculiar for its preface, in which the publisher indicates that the story was taken from the English book [20]. All editions of the Little Red Riding Hood in China are called donghua, a term that appeared in Chinese at the beginning of the twentieth century. Indeed, this expression did not appear in Chinese dictionaries until 1915, and it has not been found yet in any textbook on the history of Chinese literature. The thing is that stories or fairy tales were not considered a literary genre. However, they were popular and sparked interest in readers. The first usage of the term donghua is found in the preface to the post written by Sun Yuxiu, where he outlined the characteristics and function of donghua. According to him, it is a story written exclusively for children for educational purposes. Over time, however, as the translation practice in China developed, donghua became also intended for an adult audience [20]. In this context, the gaps that deserve particular attention are the negative effects of this kind of misunderstanding (cultural misconceptions). This problem can be eliminated with the help of the efforts of translators. All translation theories require an accurate analysis of cultural change. Thus, the same element can be endowed with a meaning that varies in accordance with the cultural system [7, 21]. The differences in expression structures lead to the differences in languages, for example, the use of a word. When cultures meet, the perception of the abundance of feelings and words that come from a foreign culture stimulates the adaptation or borrowing of this kind of wealth. This advancement is often the result of the expression of novelties through words or language styles. This is the essence of the influence of culture on translation as a new linguistic method.

\section{Problem statement}

This research is an original and reflective study of the difficulties of translation in the context of cultural and linguistic aspects and languages of two different families. It is considered how figurative Chinese words become ideograms in the process of translation. At the same time, English writing that relies on letters is distinguished by its phonetic expression. Due to the grammatical categories found in English but not in the Mandarin language, there are sometimes gaps in translation. Due to these gaps, sentences in Chinese are combined according to the speaker's intention, in other words, based on the theme and story structure. When there are no relative pronouns and relative adverbs, a certain sentence translated from a foreign language is usually broken into several sentences in the Mandarin dialect. Culture is a collection of heterogeneous conceptual elements. This is primarily due to the origin of the language, culture and extralinguistic influences throughout evolution. Thus, it is revealed that it is language that preserves all aspects of the daily life of a certain nation. Habits, history and characteristics of the nation are encrypted in the language with the help of words, proverbs and sayings [7, 21]. From this 
perspective, it seems logical, on the one hand, to consider the English version of Little Red Riding Hood to be the target one, but on the other hand, it is necessary to investigate the relationship between the English and Chinese languages and indicate potential problems in translation.

The objectives of the study are to analyze the omissions in the English version of Little Red Riding Hood and comment on the reasons for the extended Chinese version of the fairy tale. These objectives indicate a commitment to form in the transmission of linguistic information. A change in form means a loss of content. However, in fact, translators are forced to seek other means, such as omission, to ensure that the text is properly understood. Thus, strategies that meet the established requirements occur.

Tasks:

- To perform a comparative and critical analysis of the English and Chinese versions of Little Red Riding Hood by Marjolaine Leray;

- To describe the difficulties and problems of translation in two different language families (Chinese/English);

- To demonstrate omissions in both versions and comment on culturally related Chinese and English reasons for omission. Ethnocultural features of the Chinese and English languages are compared within the framework of the intercultural aspect of the translation strategy of omission.

\section{Methods and materials}

In this study, a comparative analysis is carried out using the phylogenetic method proposed by Tehrani who investigated the origin of the fairy tale Little Red Riding Hood. This method is based on the identification of genesis relationships between all living things. Tehrani studied 58 variations of the fairy tale based on 72 common features and concluded that the initial collision was transformed in accordance with the country of the region. The researcher considered folk tales as biological species, thus confirming that traditional phylogenetic methods can be used for linguistic research purposes [10]. For example, based on the theory of phylogenetic analysis, Tehrani cites Wilhelm Grimm, who argued that the traditional German tales that he and his brother Jacob had compiled were remnants of an ancient Indo-European cultural tradition that stretched from Scandinavia to South Asia [1]. The research is devoted to the Little Red Riding Hood story translated into English (E) [14] and Chinese (C) languages. The Chinese version of the story was edited and published by Qiming [20]. The omissions in the English translation and the ideology of the extended Chinese version of the tale are discussed.
The definitional analysis method, that is contrasting of lexemes or text interpretation as defined in traductology [1], helped to determine the primary source of the conflict over Little Red Riding Hood. Continuity observed in oral traditions associated with European and Chinese cultures was revealed. This fairy tale is of the international type [22]; however, fairy tale traditions are rather changeable and most international tales are artificially created. The definitional analysis with the use of the phylogenetic method allowed us to reveal the traces of cultural influences in the English and Chinese versions of the fairy tale having shown a conflict common to both cultures over the "girl in a red cape" [22] and described the themes and the ancient cultural background of both Europe and China. The authorship is often attributed to Perrault, although there is evidence that the first references to the "girl in a red cape" date back to the eleventh century [23-25]. There are assumptions that the story came to Europe from China along the Silk Road. However, it is believed [10] that the fairy tale was introduced into the culture of the Far East from Europe. Although, the Chinese version of the story is first mentioned around the same time as the French version by Charles Perrault.

At the second research stage, the comparative method and contextual analysis were used [2]. The starting point is omission (partial omission in the translation of semantically redundant words that do not contain important information and their meaning is often comprehensively restored in translation). Having compared the texts, omissions were removed from the two versions of the tale. The comparison of the translations showed that there were ten omissions in the English version and no omissions in the Chinese one. The influence of ideology of both the original and the Chinese versions was taken into account. Despite the expanded narrative of the Chinese fairy tale, the omissions in the English translation of Little Red Riding Hood did not show any accidental gaps due to the peculiarities of the English language and culture.

At the third stage of the research, the method of translation analysis associated with the description of the traditional way of thinking with the help of omissions was used. That is, after the identification of omissions in the English version of the tale, the specifics of the translation solutions used in the Chinese translation were described. This study draws attention to the practice of translation and its intercultural perspectives related to the heritage of Europe and China. A comparative synthesis accompanied by the character and narrative examples to understand the reason for the omissions in the English version of the tale is presented. 
The pinyin-based input method editing software SogouPinyin (搜 狗 拼音输入 法; pinyin: SōugǒuPinyīnShūrùfă) was used to work with the Chinese text.

\section{Research limitations}

The limitations of the study are due to the fact that the process of transferring the intercultural component was studied based on only one fairy tale. This cannot fully reflect all the features of this process, namely, eliminate linguo-ethnic barriers, neutralize the violation of semantic reception, assimilate national cultural translation while not depriving it of its national cultural identity.

\section{Results and discussion}

A comparative analysis of the English and Chinese versions of the Little Red Riding Hood revealed ten omissions. In the English text, there are six brief descriptions and four omissions (Table 1).

Ten omissions were found in the English version of Little Red Riding Hood. The phylogenetic analysis of translations showed differences in perception and cultural contexts, the use or omission of words, phrases, and details of the future life of characters and their relationship.

Most omissions are found in the narratives related to The Wolf and Little Red Riding Hood. This is, firstly, due to the fact that they are the main characters and have the biggest number of monologues, and on the other hand, these monologues contain information related to other characters; but in English, this information is in fact understood and that is why omitted.

At the same time, the Chinese version of the tale contains a lot of information on each character while in the English one, it is much harder to find a detailed description of the personality of the Mother, Grandmother, and Hunter. This is primarily due to the cultural characteristics of China. Until the twentieth century, China was a typical example of a country with a traditional social development policy, as opposed to European countries, which opened for a cultural monologue much earlier having replaced conventionalism with a more informal and at the same time laconic mentality. It took traditional China more time to integrate into the global space. The analysis of omissions illustrates the traditional way of thinking of the two different cultures (Table 2).

In these omissions, the peculiarities of intercultural exchange are traced as part of the language change. Due to the fact that a language is a system of signs, the Chinese translation describes not only linguistic signs but also the cultural message: the omission of the greeting in the English version and its detailed translation in the Chinese one. In European cultures, greeting is of minor importance but for the Chinese, it is one of the most important rituals; this is a manifestation of intercultural differences. However, in modern China, in the era of total globalization, the traditional borders have been partially erased and absorbed the components of the European mentality, which also testifies to crosscultural dependence. Chinese culture is characterized by respect for elders, a tribute to traditions, and respect for people who are higher in social status. Undoubtedly, greetings in the English language carry a similar semantic load, but due to the peculiarity of its grammatical structure, omitting or transferring a greeting during translation does not harm the context of communication [26].

A polite reply of Little Red Riding Hood to the Mother in the Chinese version. The classical model of Chinese family organization is patriarchal. The tradition is based on the Confucian standards of obedience to older relatives [2729]. The Chinese Little Red Riding Hood a priori could not fail to give a positive answer to her Mother while the English translation skips the above details.

The equivalent of "so" and "just" is not found in the Chinese text and has been replaced by the exclamation 呀 $(y \bar{a})-a h$ [30]. In the English version, the exclamation is inappropriate in this context and is replaced with "just", which fits into the structure of the English language.

A detailed description of the taste of Little Red Riding Hood in the Chinese version. Food is an important element of Chinese culture. Throughout the history of the development of Chinese culinary culture, traditions and methods of cooking that Europeans do not understand appeared. In this case, a detailed description of the girl's taste fully corresponds to the expectations of the Chinese reader. The thoughts of the Wolf in the Chinese version that Little Red Riding Hood is much tastier and her meat is more tender than that of the grandmother can be considered from the same perspective. A detailed description of the actions of the Wolf and other protagonists prompts the reader to invent possible sequels to this conflict.

The comparative analysis of the Chinese and English versions of Little Red Riding Hood showed cross-cultural and at the same time informative ideological features of the two languages: despite the fear and the ambiguous situation in the Grandmother's house, Little Red Riding Hood greets her-such behavior is a tribute to Chinese tradition of respect for elders. The state of the Grandmother is well described: she is frightened and can hardly breathe. The Chinese version has an optimistic ending for the girl while the English one does not provide any information. The fairy tale ends positively but no sequel is expected. The Chinese version of the fairy tale seems to be aimed at an older reader giving them a reason for thinking about the further narrative line. All editions of the Little Red 


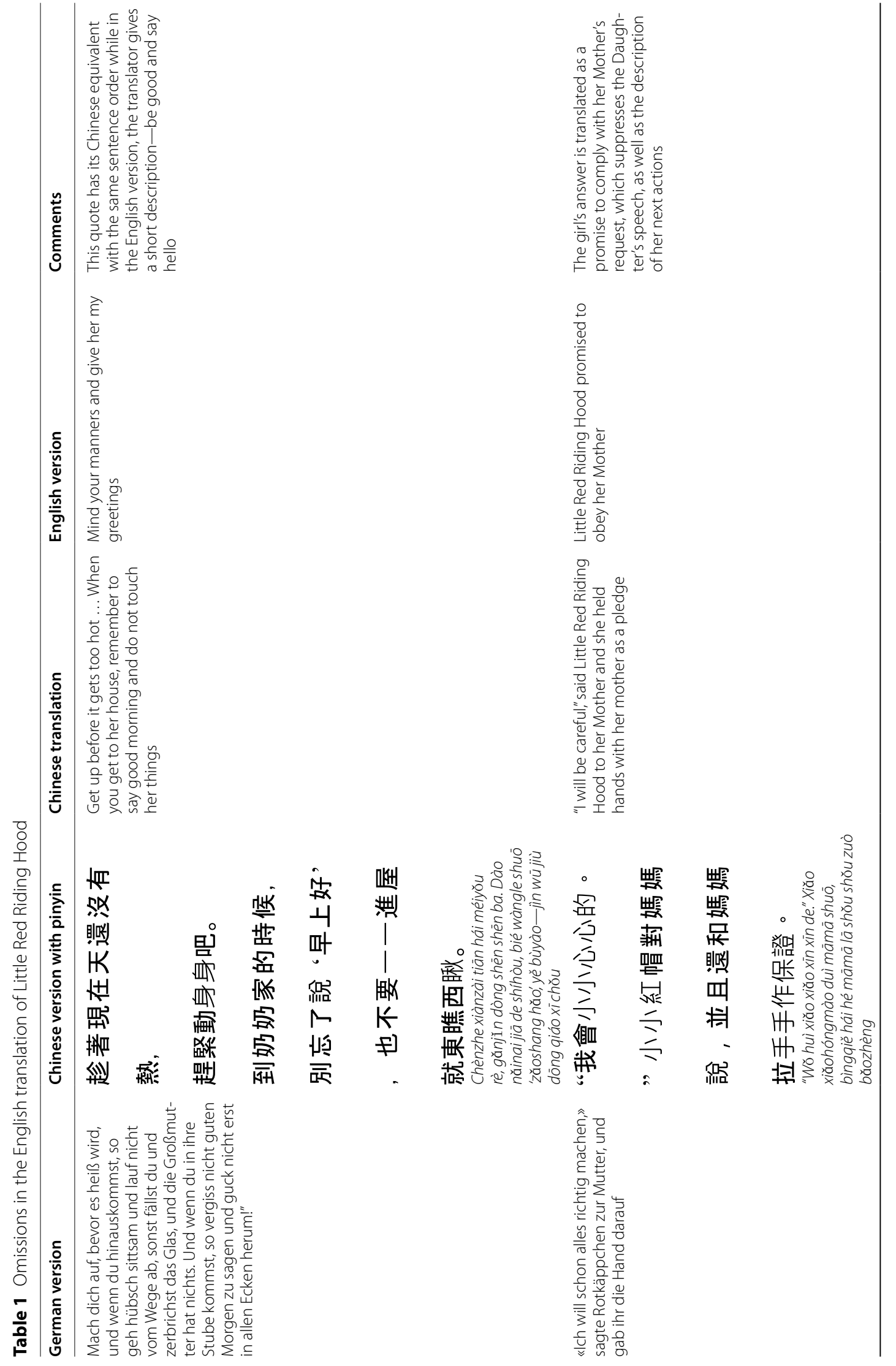




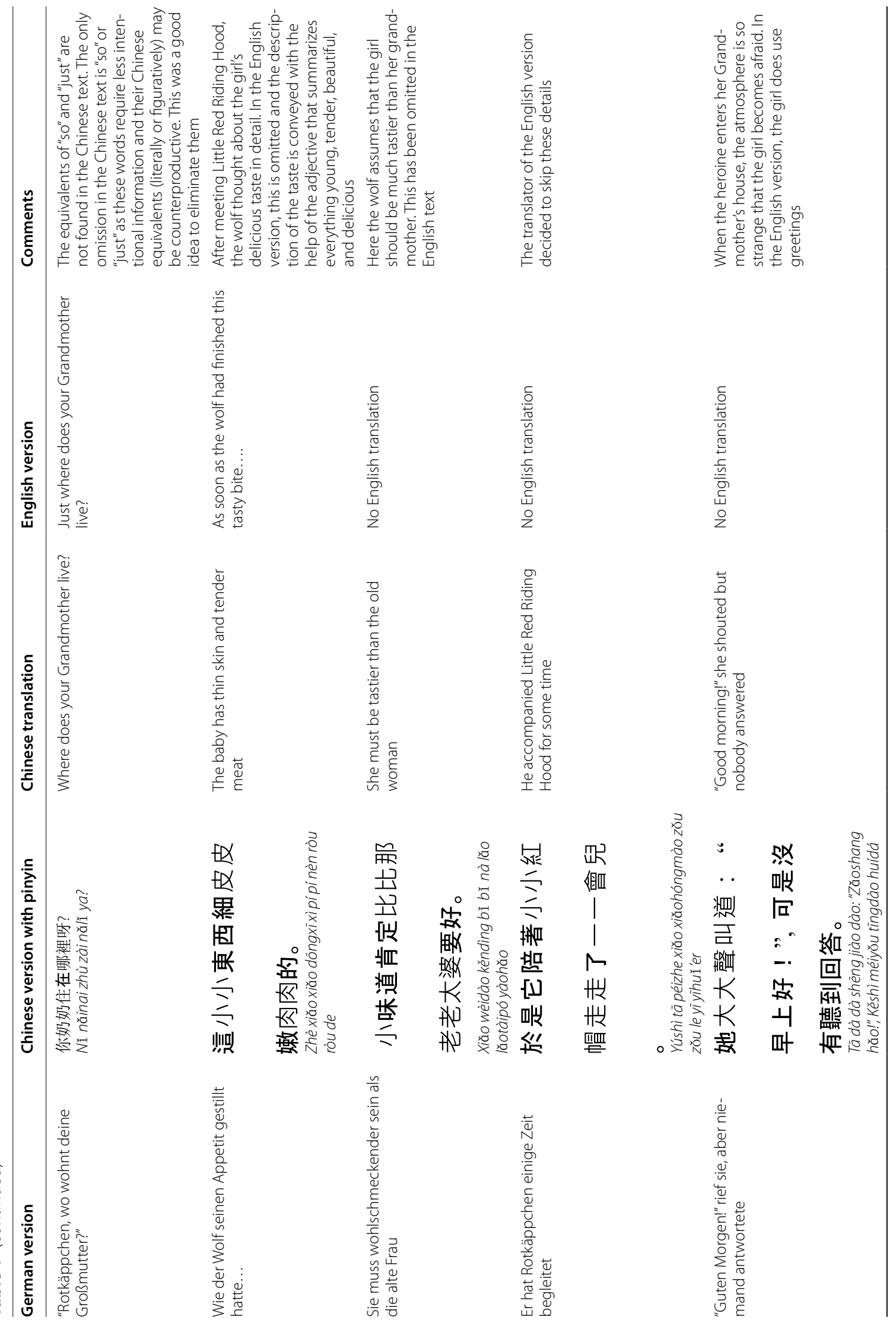




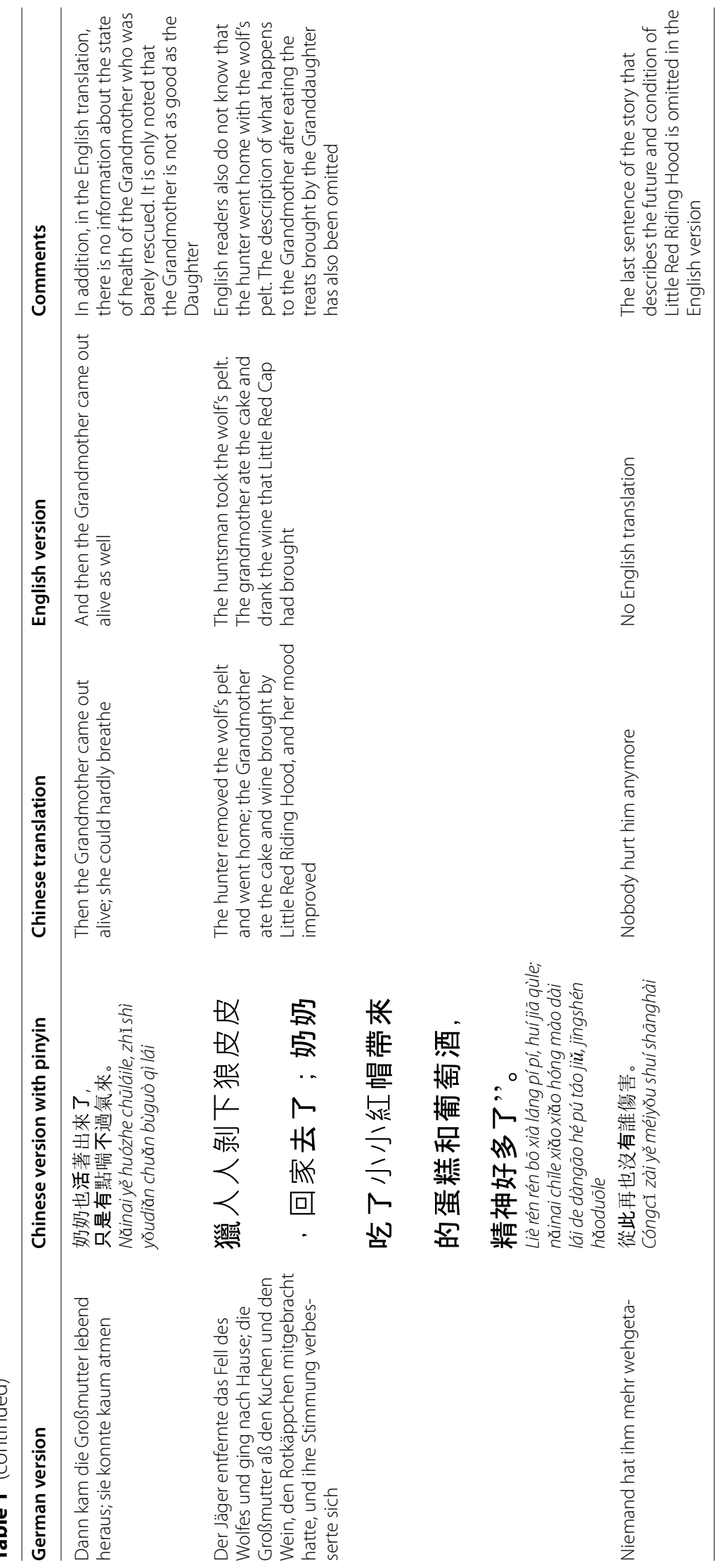


Table 2 Description of traditional thinking with the help of omissions

\begin{tabular}{|c|c|c|c|}
\hline Character & $\begin{array}{l}\text { Omission } \\
\text { number }\end{array}$ & Information omitted & Meaning of the information omitted \\
\hline The Mother & 1 & In instructions: "Say hello" and "do not touch her things" & Respect and the maternal role in raising a little girl (C) \\
\hline \multirow[t]{2}{*}{ Little Red Riding Hood } & 3 & $\begin{array}{l}\text { Greetings, promise, the character of the girl, outstretched } \\
\text { hand for greeting }\end{array}$ & $\begin{array}{l}\text { Wisdom of the girl, good relationship with the family, } \\
\text { continuation of the story (C) }\end{array}$ \\
\hline & & $\begin{array}{l}\text { An insightful situation for the girl to be remembered } \\
\text { throughout life }\end{array}$ & \\
\hline \multirow[t]{3}{*}{ The Wolf } & 3 & A range of adjectives that describe the girl's taste & The Wolf's deliberate attempt to think like a human in \\
\hline & & Comparison of the female protagonist taste & \\
\hline & & Accompaniment of the girl by the Wolf & \\
\hline \multirow[t]{2}{*}{ The Grandmother } & 2 & Complicated breathing & The fatal position of a woman (C) \\
\hline & & Rest after a dangerous day & \\
\hline The Hunter & 1 & Coming back home & Continuation (C) \\
\hline
\end{tabular}

Riding Hood in China are called donghua. Although, this term refers to children stories, it extended to older audience with time [20].

The relationship between language and culture is inseparable in the context of translation. The correspondence between two languages is conveyed by words, sentences, sentence constructions, expressions, etc. But the nature of languages cannot ensure absolute correspondence [1]. In practice, it is possible to find equivalents, but there is a risk of non-observance of the canons of the source language. Also, the meaning of a metaphor can be expressed with the help of different lexical means. Of all the aspects of linguistic correspondence, words deserve the closest attention of translators [2]. Translation should begin with a comparison and interpretation. Based on comparisons and different interpretations of the translations of the story about the girl and the wolf/the tiger, the roots of Indo-European tales are revealed. Scientists analyze the problem of the genesis and circulation of plots, their connection and transgression. The results of their studies show that contrary to the assertions of critics of the historical and geographical approach [4], the tale Little Red Riding Hood can be identified as a separate international type that evolved due to mixing elements of culture. These results demonstrate the transgression of traditional plots and provoke the hypothesis that there are intercultural relations between fairy tales $[10,22]$. The collisions of many fairy tales intersect in the context of plot, narrative, protagonism, etc. Basically, translators $[2,5]$ rely on historical and philological methods of analysis. A new trend in science is the phylogenetic methods that are actively used to reconstruct the evolutionary relationships between story types in order to trace the transition from one version to another, as well as to study their evolutionary relationships with similar plots common in Africa and Southeast Asia [10,
22]. In addition, the European school of translation [2] is based on the methods of decoding information and interpretation of the translation of elusive moments with the addition of background information by rendering the meaning of sentences in the text. Special attention is paid to the meanings of words, which results in verbalism [3]. In contrast to the European school, American scholars insist on the observance of the form, which is the law of translation [2]. The introduction of new words into the context is usually based on morphological connections. Take, for example, the translation of the story entitled Little Red Riding Hood in China. There are three types of such translations: those translated and published in mainland China; those translated in mainland China and published in Taiwan; and those translated and published in Taiwan. Scientists found six options in the first category, four in the second category, and sixty-two in the third category [19].

In most cases, the description of concepts through comparative analysis is considered to be an effective and productive approach in translation [4]. In the context of the present study, it was revealed that as a result of linguistic evolution, it is difficult for a monolingual reader to understand the meaning expressed through one word, that is, to recognize the meaning of omissions. It is interesting to consider the study [31], which reveals the issue of the classical combination of religion and literature. When talking about intercultural inheritance, it should be noted that the inspiration of the Bible in the literary circles of China spread much faster than the religion itself. This result obviously contradicts the intentions of missionaries. Due to the lack of freedom to choose a translation strategy, Chinese translators of the Bible made a literary translation of the Bible, which aroused the admiration of readers [32]; at the same time, the translators preferred to ignore the criteria that must 
be observed in intercultural translation and the religious intent was missed [32]. In order to avoid translation misunderstandings, Chinese translators used the technique of enhancing emotions [3]. Thus, the text creates an echo effect with the reader. The text is usually associated with factors such as social context, psychological state of the translators, linguistic context, etc. A similar situation is with Little Red Riding Hood translations for children aged 3-8 years who are curious and want to know why things happen. To answer all potential questions, provide a logical continuation of the story, and introduce the little ones to unfamiliar situations, Chinese translators add specific pieces of information designed to facilitate a more definite understanding of the hero's state. Children stories are often told by adults. Chinese editors have taken the initiative to use dramatic elements: they make up the main part of the story so that it can be easily read and heard. In this way, storytellers can read with different intonations and voices. Children, in turn, immerse into the story played out in front of them [18].

In the context of this study, the research [4] is of interest. The author highlights that the introduction of the omission strategy into the translation of a literary work can help to avoid the unwanted cultural connotation of the original work that is incomprehensible to the reader. Translation involves familiarization with a text in a foreign language and introduction into a foreign culture. When there is a need to satisfy the reader and the literal translation fails to meet their expectations, the strategy of omission should be used. Moreover, the translator can adhere to an additive or free translation structure. Thus, the translator can use both omission and substitution for culturally loaded words that are specific to the language into which he or she is translating the text. A translator capable of translating a version filled with linguistic effects and cultural content can reveal the complexity of reality and the unity or complete difference of the culture being described [4].

Despite the aspects of translation, in most cases, the meanings and broad meanings of words are exactly the same. The work environment of the translator is usually subject to social interference, which has an important impact on translation [33]. A quality translation can be ensured by the interlinguistic and intercultural approaches; the knowledge of two cultures is considered very important. To ensure ease of reading, it is important to understand the target culture. Instead of providing open but incomprehensible information in translation, it is necessary to help readers to correctly understand the text or at least part of the text [33].

The concept of untranslatability is associated mainly with the culture factor. We agree with [28] that, first of all, it is necessary to pay attention to the relationship between the language, culture and translation in order to choose words corresponding to ideology. For example, the omission highlighted in this study is primarily a strategy that contributes to the preservation of elements of the source culture. This method requires the translator to distinguish cultural false friends and use understandable terms with elements that exist in the recipient culture. Otherwise, the introduction of new cultural elements into the translation may be unreadable.

\section{Conclusions}

Through the example of a universal collision between the girl and the wolf/tiger reflected in the English and Chinese translations of the Little Red Riding Hood by Marjolaine Leray [20], the contrastive function of omissions and the relationship between the versions of Little Red Riding Hood and the evolution of European and Chinese moral ideology have been analyzed. In this regard, the translation strategy of omission has been chosen in the context of Tehrani's methodology. The nature of Chinese characters suggests that writing in Chinese has a more flexible structure and aesthetic style compared to English. The logic of compound symbols relates, on the one hand, to stable states of substances described by pictograms and active states determined by ideograms, and on the other hand, to people, objects and the interactive relationship of two factors. While observing the values of the source language when translating Little Red Riding Hood, Chinese translators reflected their strong traditions, humanistic spirit and idealized way of thinking depicting the problem of national, ethnic and cultural identity, the relationship between "national" and "alien". Thus, the problem of hybridity and multiculturalism in the Chinese version is still a question to discuss. The possibility of avoiding translation omissions in the Chinese language reflects the cultural traditions of China. Through the example of ten omissions found in the texts under analysis, unique phenomena and features of the content found in Chinese culture and omitted in European culture have been revealed: tradition-greeting, obedience to the older, politeness, insightful situation, disclosure of narratives of minor characters, transgression, and the potential for creating sequels. The Chinese translation of Little Red Riding Hood avoids omissions fully revealing the cultural realities of the country while the English version is characterized by conciseness. Thus, based on ten omissions playing an important role in reflecting the intercultural heritage, the mentality and consistency of the thinking of the people has been revealed.

The significance of the results obtained in the context of international practice is the disclosure of the peculiarities of the Chinese mentality for the perception of European thinking in the form of epistemes or cultural codes of a familiar system, which will reveal the paradigms of two different cultures. 


\section{Acknowledgements \\ Not applicable.}

\section{Authors' contributions}

$\mathrm{QP}$ is a single author responsible for preparation of the article. The author read and approved the final manuscript.

\section{Funding}

This paper was supported by 2020 Heilongiiang Program for Research in Philosophy and Social Sciences (Grant No. 20WWB063) "Western Marxist Paradox Poetics from the Perspective of Contemporary Anglo-American Literary Criticism". This article is the periodical achievement of Heilongjiang Program for Research in Philosophy and Social Sciences.

\section{Availability of data and materials}

Data will be available on request.

\section{Declarations}

\section{Competing interests}

This research has no competing interests.

Received: 27 September 2021 Accepted: 17 November 2021

Published online: 11 December 2021

\section{References}

1. Chirimbu SC. Rolul traducătorului în secolul XXI. Repereteoretice. Stud Ştiinț Cult. 2018;14(3):141-8.

2. Guidère M. Introduction à la traductologie: penser la traduction: hier, aujourd'hui, demain. Belgium: DeBoecksupérieur; 2016.

3. Yue M, Sun B. Translations and interlanguage in inverse translation: a case study. Across Lang Cult. 2021;22(1):45-63.

4. Kozanecka P, Matulewska A, Trzaskawka P. Methodology for interlingual comparison of legal terminology towards general legilinguistic translatology. Poznań: Wydawnictwo Naukowe CONTACT; 2017.

5. Kuznik A. La traduction comme travail: perspectives croisées en ergonomie, sociologie et traductologie. ILCEA. 2016;27:1-17.

6. Tylor EB. Primitive culture: researches into the development of mythology, philosophy, religion, art and custom, vol. 2. London: J. Murray; 1871

7. GeY. The linguocultural concept based on word frequency: correlation, differentiation, and cross-cultural comparison. Interdiscip Sci Rev. 2021. https://doi.org/10.1080/03080188.2021.1946743.

8. Tateishi K. Phonology of Sino-Japanese morphemes. Univ Mass Occas Pap Linguist. 1990:13(1):10.

9. Xiaolong W, Qingcai C, Yeung DS. Mining Pinyin-to-character conversion rules from large-scale corpus: a rough set approach. IEEE Trans Syst Man Cybern. 2004;34(2):834-44.

10. Tehrani JJ. The phylogeny of little red riding hood. PloS ONE. 2013;8(11):e78871.

11. Hall ET. The silent language in overseas business. Harv Bus Rev. 1960:38(3):87-96.

12. Zheng W, Jin S, Liu C, Xu F. An analysis of the spatial characteristics of intercultural communication of intangible cultural heritage: a case study of shadow drama. Geogr Sci Res. 2018;7(4):363-71.

13. Zhang W, Walker S, Evans M, Bennett J. Inheritors of the Yellow River: the relationship of heritage making practices to cultural self-confidence in China. Int J Anthropol Ethnol. 2021;5(1):4.

14. Leray M, Ardizzone S. Little red hood. Waterford: Phoenix Yard; 2011

15. Kaya M, Halford WK, Hiew DN, Sheffield J, Van De Vijver FJ. Ethnic identification and relationship satisfaction in Chinese, Western, and intercultural Chinese-Western couples. Couple Fam Psychol Res Pract. 2019;8(3):121-36.

16. Ortiz P, Ortiz R, Martín JM, Rodríguez-Griñolo R, Vázquez MA, GómezMorón MA, et al. The hidden face of cultural heritage: a science window for the dissemination of elementary knowledge of risk and vulnerability in cultural heritage. Herit Sci. 2018;6(1):60.
17. National Central University. The compilation and spread of the fairy tale "Little Red Riding Hood" in Taiwan (1945-2010). Taiwan: National Central University; 2012.

18. Sendak M, Zinsser W. Worlds of childhood: the art and craft of writing for children. Boston: Houghton Mifflin Harcourt; 1998.

19. Zhengzhong Bookstore. General catalogue of children's books of the Republic of China. Taipei City: Central Library; 1967.

20. Green Y, Green W. The complete works of Grimm's fairy tales. Taipei City: Qiming Publishing House; 1953.

21. Longxi Z. The complexity of difference: individual, cultural, and crosscultural. Interdiscip Sci Rev. 2010;35(3-4):341-52.

22. Da Silva SG, Tehrani JJ. Comparative phylogenetic analyses uncover the ancient roots of Indo-European folktales. R Soc Open Sci. 2016:3(1):150645.

23. Chih-chun $H$, Chengzeng $H$, Specht A, Lontzen G, Barchilon J. The earliest version of the Chinese "Little Red Riding Hood": the tale of the Tigerwoman. Merveilles Contes. 1993;7(2):513-27.

24. Luo W. The fairy-tale girl in Chinese culture: comparing female protagonists in the western and Chinese fairy-tales. Doctoral dissertation. Portugal: Literatura e Cultura Inglesas; 2019.

25. Wulandari D. Words reflecting violence in Grimm's little red cap and little snow white: a corpus-based study. Dissertation. Malang: Universitas Negeri Malang; 2018

26. Glushkova SY. Linguistic and pragmatic aspects of the politeness category in English and Chinese. Author's abstract. Kazan: Tatar State Humanitarian Pedagogical University; 2011.

27. Halford WK, Leung PW, Hung-Cheung C, Chau-Wan L, Hiew DN, van de Vijver FJ. Relationship standards and relationship satisfaction in Chinese, Western, and intercultural couples living in Australia and Hong Kong, China. Couple Fam Psychol Res Pract. 2018;7(3-4):127-42.

28. Yongqi L, Ruixia Y, Pu W, Anlin Y, Guolong C. A quantitative description of the spatial-temporal distribution and evolution pattern of world cultural heritage. Herit Sci. 2021;9:80.

29. O'Dwyer S. Deflating the 'Confucian Heritage Culture' thesis in intercultural and academic English education. Lang Cult Curric. 2017:30(2):198-211.

30. Xu HL, Moloney R. Moving between diverse cultural contexts: how important is intercultural learning to Chinese heritage language learners? In: Interculturality in Chinese language education. London: Palgrave Macmillan; 2017. p. 151-76.

31. Lessard-Clouston M, Lu P. Bible translation and scripture engagement: how to introduce scripture to minority cultures in China. In: ISAL 668 seminar in applied linguistics. Iceland: ISAL; 2017.

32. Zetzsche JO. The Bible in China: the history of the Union Version or the culmination of protestant missionary Bible translation in China. Milton Park: Routledge; 2017

33. Zhang J, Wu Y. Seventy years of Chinese - anthropology. Int J Anthropol Ethnol. 2021;5(1):7.

\section{Publisher's Note}

Springer Nature remains neutral with regard to jurisdictional claims in published maps and institutional affiliations.

\section{Submit your manuscript to a SpringerOpen ${ }^{\circ}$ journal and benefit from:}

- Convenient online submission

$\checkmark$ Rigorous peer review

- Open access: articles freely available online

- High visibility within the field

- Retaining the copyright to your article

Submit your next manuscript at springeropen.com 